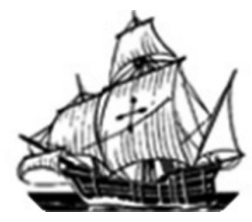

Nau Literária: crítica e teoria de literaturas • seer.ufrgs.br/NauLiteraria

ISSN 1981-4526・ PPG-LET-UFRGS • Porto Alegre • vol. 09, n. 01 • jan/jun 2013

Dossiê: Voz e Interculturalidade

\title{
BIBLIOTECA PÚBLICA: UM LUGAR PARA "ENCANTADORES" DE HISTÓRIA - O Caso da Hans Christian Andersen
}

\begin{abstract}
Samuel Frison (UFRGS - sfrison@terra.com.br)
Faço com que as pessoinhas acreditem que há uma magia por trás das palavras: magia esta que só pode ser capturada por ${ }^{l}$ um ouvido interior que foge a razão. Ninguém pode querer ouvir a narrativa da criação do mundo com ouvidos racionais. É preciso ouvi-la com o coração. (Mundukuru - Janelas da imaginação, experiências singulares com os contos da tradição oral e outras histórias)
\end{abstract}

RESUMO: O presente relato pretende mostrar a importância da biblioteca pública na disseminação da cultura oral e na formação dos contadores de histórias, bem como na divulgação das suas práticas, mediando atividades de leitura e realizando performances. A metodologia utilizada é o estudo de caso. Para tanto analisa a Biblioteca Pública Infantil Hans Christian Andersen, localizada no bairro do Tatuapé, na cidade de São Paulo, que promove, desde 2008, o curso de Formação para Contadores de Histórias. A unidade de informação dissemina a prática das poéticas orais, incentiva à formação de contadores de história e respeita os princípios determinados pelo Manifesto da UNESCO e da IFLA (Internacional Federation of Library Associations) para bibliotecas públicas. No entanto, o utilitarismo que tem impregnado os órgãos públicos de acesso à cultura e a pressão por sua verba de manutenção, aliado ao espírito tecnocrata e neoliberal, têm ameaçado esse patrimônio. A biblioteca, enquanto espaço cultural, precisa atender aos índices de frequência, mostrando resultados. Nessa tensão entre custos e resultados, o espaço e seus colaboradores mantêm viva sua ligação com a comunidade e cumprem seu dever de aproximar leitores, além de prestar um serviço de cidadania aos seus usuários, transformando a arte de contar história em arte de encantar, daí a poética dos "encantadores de histórias".

Palavras-chave: Contadores de História. Bibliotecas. Oralidade.

ABSTRACT: This report aims to show the importance of the public library in spreading the culture and training of oral storytellers, as well as dissemination of their practices , mediating reading activities and conducting performances. The methodology used is the case study . For both analyzes the Public Library Children's Hans Christian Andersen, located in the neighborhood of Tatuapé , in São Paulo, which promotes, since 2008 , the Training Course 
for Storytellers . A unit of information disseminated practice of oral poetry, encourages the formation of storytellers and respects the principles determined by the Manifesto of UNESCO and IFLA ( International Federation of Library Associations) for public libraries . However, utilitarianism that has permeated public bodies access to culture and the pressure for their maintenance budget, coupled with the spirit and neoliberal technocrats, have threatened that heritage. The library as a cultural space, must meet the attendance rates, showing results. In this tension between costs and results, the space and its employees keep alive their connection with the community and do their duty to bring readers, in addition to providing a service of citizenship to their users, turning the art of storytelling in art to enchant, then the poetics of " charming storytellers."

Key-words: Storytellers. Libraries. Orality

\section{INTRODUÇÃO}

O presente relato de experiência busca descrever a importância da Biblioteca Pública enquanto instituição viva dentro da cultura local e sua predisposição para o diálogo receptivo com outras culturas que dela se apropriam. Também sobre a necessidade de utilização do espaço da biblioteca para disseminar as práticas de contadores de histórias enquanto forma de agregar pessoas e suas experiências num mundo que caminha para a virtualização das relações. Para tanto, busco o exemplo de práticas efetivas realizadas pela Biblioteca Pública Hans Christian Andersen, localizada na Avenida Celso Garcia, 4142, no bairro do Tatuapé, zona Leste da capital paulista. A escolha deste espaço como estudo de caso se justificada pela história do lugar na promoção da cultura oral, da sua enorme aceitação pela população que visita a biblioteca para prestigiar as práticas e fazer parte delas o que torna ao espaço referência e manifesto para a sobrevivência da biblioteca pública enquanto patrimônio da cultura.

O estudo de caso se configura como a indicação de um objeto específico sobre o qual se pode inferir ou sistematizar uma reflexão acerca de um tema e assunto, aqui no caso as bibliotecas públicas como espaços estratégicos para disseminação da oralidade e das práticas envolvendo os contadores e suas memórias afetivas. Está inserido dentro do expresso por Moreira e Caleffe (2006, p.73) enquanto uma pesquisa de caráter qualitativo, pois "explora as características dos indivíduos e cenários que não podem ser descritos numericamente." Nessa perspectiva se baseia na observação, entrevista e coleta de dados de uma comunidade de pessoas que constituem e modificam o ambiente cultural através de ações culturais significativas. 
A Biblioteca Pública Hans Christian Andersen foi inaugurada no dia 5 de julho de 1952, na região do Tatuapé, em São Paulo. Desde a sua concepção até os dias de hoje, ela se tornou uma biblioteca temática com o intuito de atrair principalmente o público mirim e disseminar a literatura infantojuvenil, tornando-se um espaço que trabalha com a imaginação e a fantasia. Possui uma programação cultural intensa que engloba ações variadas como contação de história, música infantil, teatro, dança, artes plásticas, sempre envolvendo assuntos de igual importância ligados à cultura oral e escrita e que remontam às fábulas, as lendas, os mitos, as parlendas, as cantigas de roda, entre outras manifestações artísticas que englobam o imaginário da infância. Desenvolve vários projetos sociais voltados para essa área, procurando resgatar a experiência da criança com o universo onírico. Por isso a partir de 1995 foi condecorada como biblioteca especializada em contos de fada.

A Hans Christian Andersen, enquanto biblioteca temática, é a segunda nesta categoria criada na cidade de São Paulo. Sua precursora, a Biblioteca Pública Monteiro Lobato, foi criada em 1936 no centro da cidade, é fruto da gestão do escritor Mario de Andrade a frente do recém criado Departamento de Cultura do Município, cuja sessão de bibliotecas foi administrada por Rubem Borba de Moraes na gestão do prefeito Fábio Prado. Atualmente a Hans conta com um acervo de 31 mil livros infantis e desde o ano de 2008 oferece semestralmente trinta e cinco concorridas vagas para o curso de formação de contadores de história.

Isso não significa que ela atenda apenas ao público infantil. Muito pelo contrário. Grande expressão de seus frequentadores é de gente grande que não perdeu o hábito de se reportar a essa época importante de nossa vida, a infância, cujas lembranças são tão importantes para estruturação de nossa personalidade dita adulta Como bem lembra a música de Milton Nascimento, "Bola de Meia, Bola de Gude", "há um menino, há um moleque, pulando sempre no meu coração, toda vez que o adulto balança, ele vem pra me dar a mão". Essa persona da criança que habita o adulto é resgatada tanto pela memória enquanto instrumento de resgate, quanto pela encenação proporcionada pelo jogo da contação de histórias em que um entre-lugar se cria pelo cruzar do passado com o presente. Como afirma Matos (2005, p. 1):

Os contadores de histórias são guardiões de tesouros feitos de palavras, que ensinam a compreender o mundo e a si mesmos. Eles semeiam sonhos e esperanças. São carinhosamente chamados de gentes das maravilhas pelos árabes. Eles contam histórias de príncipes 
e gênios do mal, animais encantados e heróis que passam por difíceis provações para merecera princesa, de velhos sábios e de bruxas, de animais que falam e agem como humanos.

Todo o universo onírico no qual se situa essa arte de encantar grupos através de relatos maravilhosos que suspendem a vida presente por um momento e fazem o espectador se entregar ao que lhe dado pela palavra suscita definições para tentar entender a figura do contador. Como ilustra Pavis (1999, p. 69) na definição desse contador sob um aspecto mais arte-educativo:

O contador de histórias é um artista que se situa no cruzamento de outras artes: sozinho em cena (quase sempre), narra sua ou uma outra história, dirigindo-se diretamente ao público, evocando acontecimentos através da fala e do gesto, interpretando uma ou várias personagens, mas voltando sempre ao seu relato. Relatando os laços com a oralidade, situa-se em tradições seculares e influencia a prática teatral do ocidente, confrontando-se com as tradições esquecidas da literatura popular, como o relato do contador de histórias árabe ou do feiticeiro africano. O contador de histórias (que muitas vezes compõe seus próprios textos) procura estabelecer contato direto com o público reunido numa praça por ocasião de uma festa, ou uma sala de espetáculos; ele é um performer que realiza uma ação e transmite uma mensagem poética diretamente recebida pelos ouvintes espectadores. Como nas tradições orais, a memorização do texto e do gesto é efetuada simultaneamente.

\section{O CURSO DE FORMAÇÃO PARA CONTADORES DE HISTÓRIA}

Desde a década de 1990 até o início do século XXI, a arte de contar histórias e a procura por respectivos espaços de diálogo em torno da ação e partilha de saberem vem se concretizando. Festivais internacionais e locais se organizam, grupos se formam, ações se disseminam. A pergunta que surge é porque tais interesses têm se fundamentado quando as perspectivas de comunicação e lazer se voltam cada vez mais para esfera do virtual? Matos (2006, p. 1) instiga a pensar quando denomina tal fenômeno como peculiar, uma vez que “coisas como essas são estranhas à nossa contemporaneidade - frenética, tecnológica, barulhenta e acesa a néon - em que a necessidade é comunicar de forma cada vez mais rápida e sofisticada e o desejo pelo novo é insaciável." A resposta para tal indagação da necessidade de se contar e ouvir histórias está ligada à própria necessidade do ser humana sobreviver 
enquanto espécie que guarda uma história, uma identidade, um saber a ser partilhado ou recuperado em sua memória de afetos. Tal ação se constrói como uma prática que vai ao sentido oposto ao da pós-modernidade tecnológica e pulverizada de signos.

Há a necessidade de se perguntar se para contar uma boa história é necessário formação ou se o contador de história é a priori um sábio que espontaneamente narra os feitos guardados pela memória. Para a geração que nasceu sob a influência da internet e da tecnologia, a que se resgatar essa voz interior que parece estar cochilando. Para os que já cultuam a arte de encantar pela voz dos contadores, o curso de contadores de histórias é uma possibilidade de partilhar saberes e repertório. Nesse sentido, ele surge no espaço da biblioteca como uma oportunidade para o encontro e o diálogo.

Para se candidatar a uma vaga no curso de formação de contadores de história da Hans Christian Andersen os pré-requisitos são uma carta que o candidato deve elaborar justificando os motivos que o levaram a procurar a formação. É necessário também ter mais de 18 anos e não é exigido qualquer comprovante de escolarização. O que conta realmente são as palavras que traduzem as intenções dos contadores. Os professores do curso são atores, historiadores, pedagogos, escritores, pessoas ligadas à cultura de uma forma geral e que durante suas carreiras desenvolveram e disseminaram a arte de contar histórias. Atualmente o curso conta com sua décima quarta turma, oferecida semestralmente, sempre com uma concorrência bastante acirrada, o que torna a seleção uma tortura de culpas para os seus organizadores.

Ana Luísa Lacombe, contadora de histórias e atual coordenadora do curso, afirma que o processo seletivo é uma prova de fogo, muito difícil, pois as palavras escritas seduzem. Fica-se constrangido ao ter de preterir alguém por detalhes para dar lugar a outros. Os insistentes sempre conseguem aprovação. A ideia, diante da demanda, é criar novas turmas, no entanto para isso, o espaço local não comporta e a agenda dos professores é intensa. $\mathrm{O}$ público que se candidata é o mais variado possível: educadores, bibliotecários, donas de casa, psicólogos, psicopedagogos, profissionais do mundo coorporativo, atores. Todos trazem suas experiências como contadores imbuídos pelo aperfeiçoamento na arte de contar histórias. Alguns já são contadores natos. Outros vêm em busca de novos recursos. Como afirma Machado isso não significa que os não contemplados com o dom não possam contar histórias muito bem. Pelo contrário. "O dom de contar histórias é na verdade, um exercício constante, um aprimoramento contínuo de possibilidades internas de ver o mundo de outras formas." (2004, p. 73). 
O trabalho final é um sarau organizado pela biblioteca que entrega à comunidade, através do empenho dos alunos, uma apresentação cuja preparação ainda leva a consideração o seu maior trunfo: a palavra enternecida e entretecida. Todos aprendem uns com os outros, pois há pessoas de várias regiões do país, com repertório variado. As trocas são muitas. São Paulo é o grande corredor do Brasil. Por lá circulam pessoas de diversas culturas. É assombrosa, claustrofóbica, suja e barulhenta. Mas no que concerne à cultura nacional, é um grande caldeirão, uma possibilidade grande para aprender, se você estiver aberto e disposto.

Dessa forma a disseminação da arte de contar histórias se estende nas ações desempenhadas pelos alunos quando o curso se conclui na forma de serviços ou ações que passam a desempenhar em espaços culturais, terapêuticos e educacionais da cidade. Atualmente a cidade de São Paulo conta com 65 bibliotecas públicas, incluindo os Centros Educacionais Unificados (CEUS) que oferecem atividades que envolvem mediação da leitura e contação de histórias. Essa demanda pela arte de ouvir e contar é resgatada pela fundadora do curso de contadores de história da Hans Christian Andersen, a arte educadora Alice Bandini.

Houve a partir da década de 1990 e posteriormente nos anos 2000 uma cobrança muito grande por parte dos funcionários da rede de bibliotecas que sentiam necessidade de uma formação especial para contarem histórias em suas unidades e mediar leitura. Também uma enorme demanda de interesse de profissionais de outras instituições interessados nessa arte.

Por causa da internet, houve uma diminuição sensivel na frequência, particularmente nas salas de pesquisa. Essa mudança levantou a discussão sobre os novos rumos no atendimento da biblioteca pública e seu papel nas comunidades onde estão inseridas. Uma das nossas propostas era a de, além de adotar medidas para a modernização das bibliotecas, instalando computadores, catálogos eletrônicos, realizamos atividades culturais para atrair maior número de público espontâneo, entre elas, a denominada Hora do Conto. (BANDINI, 2012, p. 87).

Quando a Biblioteca Hans Christian Andersen foi laureada como temática em Contos de Fadas, no ano de 1995, era o momento de, além de oferecer palestras, oficinas, horas do conto e teatro infantil voltados ao tema, incluir nessa programação um curso especial, com 60 horas de duração (o mais longo fora dos meios acadêmicos no país), com o objetivo de atender aos inúmeros pedidos, abrindo as inscrições aos interessados e, principalmente, com a 
intenção de formar multiplicadores dessa arte, conscientes da importância e da força que essa atividade exerce sobre as pessoas.

Embora a maioria os pedidos fosse voltada para a questão técnica (uso do corpo, voz, objetos), havia a preocupação de abordar os aspectos afetivos e literários, para que os participantes do curso, futuros mediadores de leitura e multiplicadores desenvolvessem um trabalho com mais consciência e qualidade do conteúdo. Assim nasceu o curso e por ele já passaram cerca de 500 contadores.

\section{BIBLIOTECA PÚBLICA: LUGAR PARA CONTADORES DE HISTÓRIA}

O Manifesto da UNESCO/IFLA (Internacional Federation of Library Associations) para bibliotecas públicas criado em 1994 contempla vários objetivos que as bibliotecas públicas no mundo necessitam aderir como o apoio à tradição oral, o fomento ao diálogo intercultural e à diversidade cultural, a promoção do conhecimento sobre a herança cultural e o apreço às artes em geral. Também atender às expressões advindas das diversas culturas onde a biblioteca está inserida. Porém, o utilitarismo social que tem impregnado os órgãos públicos de acesso à cultura e a pressão por sua verba de manutenção, aliado ao espírito tecnocrata e neoliberal e a explosão da cultura digital, têm ameaçado esse patrimônio. É o que vemos hoje em países como a Inglaterra que no ano de 2010 fechou mais de 400 bibliotecas públicas em vista da digitalização de seus acervos e pela contenção de custos.

No caso do Brasil, o acesso à cultura e às bibliotecas ainda é restrito. Muitas cidades nem possuem bibliotecas e muitas escolas de grandes metrópoles não contam com uma. Existem até casos de escolas particulares restringindo ações na biblioteca. Nosso número de leitores ainda é pequeno se comparado a países como Colômbia, por exemplo, que utilizaram a Biblioteca Pública como medida de acesso ao letramento e à alfabetização e forma de agregar pessoas, diminuindo problemas sociais como o narcotráfico e a pobreza. Nesse sentido, a função social do bibliotecário deve romper com o paradigma do tecnicismo que impera nos cursos de formação, aliando-se a pedagogos, a professores e artistas que, de alguma forma, resgatam a memória, a tradição e afetividade através da arte de contar histórias em seus espaços de atuação. Como lembra Silvia Castrillón, temos urgência de um bibliotecário disseminador que resgate o papel de protagonismo das bibliotecas na promoção e resgate da memória e da cultura. Para isso deve assumir sua posição política diante do mundo enquanto aquele intelectual que luta pela alfabetização em todos os níveis, pelo acesso 
a todas as manifestações culturais de todos os povos, na forma oral e escrita, porque assim de faz a democracia e se diminui as desigualdades sociais.

Tenho razões para crer que ganharíamos muito se inscrevêssemos os programas de incentivos à leitura e à escrita em projetos políticos de mudança social, de participação, de democratização, para os quais a melhora na educação é condição básica. O enorme desejo das classes populares de nossos países de superar sua situação, de melhorar suas condições de vida, sua vontade de aprender e de saber; o modo como essas classes se organizam para resolver seus problemas mais imediatos; os laços de solidariedade que se estabelecem para, por exemplo, organizar bibliotecas populares, têm a intuição de que nessas bibliotecas se pode encontrar um instrumento que lhes permita melhorar, ao menos, a vida de seus filhos - seguir adiante, conforme expressões corrente entre os setores populares - são algumas dessas razões. (CASTRILLÓN, 2013, p. 63)

Sempre que alguém entoa o "Era uma vez....." surge a necessidade de parar. Imediatamente somos chamados por uma vez que é presente, mas nos remonta a um tempo passado. Dessa forma somos fisgados por alguém que em alguma época de nossa vida nos acalentou pelas palavras. Quem não passou por esta experiência na infância, certamente não obteve a mais rica de todas as experiências, o contato mais profundo de sua existência em relação ao seu eu. Winnicot nos fala da zona ou espaço transicional, lugar de projeções das nossas afetividades na superação das adversidades no complexo psicanalítico. No mundo embotado de virtualidades, onde as pessoas são movidas pela imagem do parecer, mais do que nunca surge a necessidade do encontro com esse nosso "eu" mais profundo a ser desvelado, que pode vir entretecido pela voz do contador de histórias.

Nessa perspectiva, as bibliotecas públicas, através de projetos como o desenvolvido pela Hans Christian Andersen, têm sua relevância, que vai muito além do levantamento do número de frequentadores exigida pela tecnocracia à sombra do utilitarismo imediato. Aperfeiçoar o uso da palavra para torná-la viva, vibrante, na necessidade de emocionar as pessoas em seu linguajear é papel do contador de histórias. Através da atenção dispensada à sua voz pode-se capturar o que há de melhor em nossa função simbólica configurada na emoção. Mas para isso é necessário recuperar o que há de mais simples e mais complexo num mundo repleto de ruídos: a capacidade de escutar e de escutar-se. Nesse sentido, memória, oralidade e afetividade são elementos cúmplices resgatados pela arte de contar histórias. Mais do que nunca, faz-se necessária à presença dos encantadores de histórias no processo de 
resgatar essas imagens que moram em todos nós ou pelo menos para destravar e se permitir sonhar. Assim, como no poema de Mário Quintana, o menino poderá conversar com o velho pai que o habita sem se assustar com a imagem que vê. No atual contexto, bibliotecas públicas como a Hans Christian Andersen são mais do que necessárias.

\section{REFERÊNCIAS BIBLIOGRÁFICAS}

BANDINI, Alice. A arte de contar histórias e a biblioteca pública. In: A arte de encantar - o contador de histórias contemporâneo e seus olhares. São Paulo: Editora Cortez, 2012.

CASTRILLÓN, Silvia. O direito de ler e de escrever. São Paulo: Pulo do Gato, 2013.

IFLA/UNESCO. Manifesto sobre Bibliotecas Públicas. Disponível em http://archive.ifla.org/VII/s8/unesco/port.htm. Acesso em 04 de maio de 2013.

MACHADO, Regina. Acordais. Fundamentos Teóricos-Poéticos da Arte de Contar Histórias. São Paulo: Difusão Cultural do Livro, 2004.

MATOS, Gislayne Avelar. A palavra do Contador de Histórias. São Paulo: Martins Fontes, 2005.

MOREIRA, Herivelto, CALEFFE, Luiz Gonzaga. Metodologia da Pesquisa para o Professor Pesquisador. Rio de Janeiro: Lamparina, 2006.

MUNDUKURU, Daniel. Janelas da Imaginação, experiências singulares com os contos da tradição oral e outras histórias. São Paulo: Espaço Pedagógico, 2000.

PAVIS, Patrice. Dicionário de Teatro. São Paulo, Perspectiva, 1999.

WINNICOT, D.W. O brincar e a realidade. Rio de Janeiro: Imago, 1975. 